\title{
Simulasi Numerik Reaksi Fusi Nuklir dengan menggunakan Metode Wong
}

\author{
Muhammad Zamrun Firihu, Viska Inda Variani, Justina \\ Jurusan Fisika, FMIPA, Universitas Halu Oleo, Kampus Hijau Bumi Tridharma \\ Anduonohu, Kendari, Sulawesi Tenggara, 93232 \\ viskadhani@yahoo.co.id
}

Received 20-01-2016, Revised 10-02-2016, Accepted 17-03-2016, Published 20-04-2016

\section{ABSTRAK}

Simulasi numerik untuk menghitung tampang lintang reaksi fusi nuklir yang melibatkan intiinti ringan telah dilakukan dengan menggunakan formula Wong. Reaksi-reaksi fusi nuklir yang dikaji dalam penelitian adalah ${ }^{12} \mathrm{C}+{ }^{12} \mathrm{C},{ }^{16} \mathrm{O}+{ }^{12} \mathrm{C}$ dan ${ }^{16} \mathrm{O}+{ }^{16} \mathrm{O}$. Hasil simulasi perhitungan tampang lintang yang diperoleh dengan menggunakan formula Wong kemudian dibandingkan dengan hasil eksperimen. Untuk memeriksa keakuratan hasil perhitungan dibandingkan dengan hasil ekperimen maka dilakukan perhitungan nilai Chi-kuadrat. Hasil perhitungan tampang lintang dan nilai Chi-kuadrat menunjukkan bahwa hasil simulasi dapat menjelaskan data eksperimen tampang lintang reaksi fusi bagi reaksi-reaksi yang dikaji. Hasil ini menunjukkan bahwa formula Wong dapat digunakan untuk mengkaji reaksi fusi nuklir yang melibatkan intiinti ringan.

Kata kunci: Formula Wong, Reaksi Fusi Nuklir, Tampang Lintang, Chi-kuadrat

\section{ABSTRACT}

\begin{abstract}
The numerical simulation for calculating the cross section of fusion reaction is done by using Wong formula. We especially calculated the cross section for the fusion reaction of light systems, i.e. ${ }^{12} \mathrm{C}+{ }^{12} \mathrm{C}$, ${ }^{16} \mathrm{O}+{ }^{12} \mathrm{C}$ and ${ }^{16} \mathrm{O}+{ }^{16} \mathrm{O}$ reactions. We compared the obtained cross section with experimental data. In order to check the accuracy of the calculations, the chi-square analisys is then permormed. We found that the simulation results of the fusion cross section obtained using Wong Formula well explain the experimetal data of the fusion cross section for the ${ }^{12} \mathrm{C}+{ }^{12} \mathrm{C},{ }^{16} \mathrm{O}+{ }^{12} \mathrm{C}$ and ${ }^{16} \mathrm{O}+{ }^{16} \mathrm{O}$ reactions. This finding indicates that the Wong formula can be used for studing the fusion reaction of light systems.
\end{abstract}

Keywords: Wong Formula, fusion reaction, cross section, Chi Square

\section{PENDAHULUAN}

Reaksi inti adalah proses perubahan yang terjadi dalam inti atom. Reaksi inti atau biasa disebut dengan reaksi nuklir merupakan interaksi antara dua buah inti atom atau partikel inti atom yang saling bertumbukan sehingga menghasilkan inti atom baru disertai pelepasan energi. Prosesnya terjadinya reaksi nuklir antara sebuah inti proyektil $a$ dan inti target $X$ dan menghasilkan sebuah inti $Y$ dan sebuah partikel $b$ dapat dijabarkan sebagai berikut

$$
a+X \rightarrow Y+b \text { atau } X(a, b) Y
$$

$a=$ inti atom proyektil, $b=$ partikel hasil, $X=$ inti atom target, $Y=$ inti hasil reaksi. Jika proses reaksi inti menghasilkan inti hasil reaksi memiliki nomor massa dan jumlah proton yang lebih besar maka reaksinya lebih dikenal sebagai reaksi fusi nuklir. Inti-inti berat yang terbentuk dapat stabil karena pengaruh gaya ikat nuklir atau yang dikenal sebagai gaya inti agar supaya memberikan gaya ikat nuklir lebih kuat dari gaya tolak menolak Coulomb ${ }^{[1]}$. Contoh reaksi fusi nuklir adalah: 


$$
{ }_{1}^{1} \mathrm{H}+{ }_{1}^{3} \mathrm{H} \rightarrow{ }_{2}^{4} \mathrm{He}+{ }_{0}^{1} n+17,59 \mathrm{MeV}
$$

Dimana,

${ }_{1}^{2} H=$ deuterium (inti proyektil)

${ }_{1}^{3} \mathrm{H}=$ tritium (inti target)

${ }_{2}^{4} \mathrm{He}=$ Helium (inti atom baru)

dan ${ }_{0}^{1} n=$ neutron $^{[2]}$.

Secara eksperimen untuk melihat seberapa besar peluang terjadinya reaksi fusi nuklir dilakukan melalui pengukuran tampang lintang reaksi fusi dimana semakin besar nilai tampang lintang yang terukur maka pekuang terjadinya reaksi juga semakin besar. Dalam makalah ini simulasi numerik untuk melakukan proses perhitungan tampang lintang reaksi fusi dilakukan dengan menggguakan formula Wong yang diturunkan secara analitik dengan menggunakan asumsi model serapan kuat gelombang berjalan (ingoing-wave strong-absorption $)^{[3]}$. Beberapa studi telah dilakukan untuk menjelaskan data eksperimen tersebut ${ }^{[4-9]}$. Reaksi-reaksi fusi yang ditinjau adalah reaksi fusi yang melibatkan inti-inti ringan yaitu ${ }^{12} \mathrm{C}+{ }^{12} \mathrm{C},{ }^{16} \mathrm{O}+{ }^{12} \mathrm{C}$ dan ${ }^{16} \mathrm{O}+{ }^{16} \mathrm{O}$ dimana data eksperimen tampang lintangnya telah diperoleh $[10,11,12,13,14]$. Dalam makalah ini dilakukan proses simulasi secara simultan sehingga diperoleh visualisasi hasil perbandingan antara teori dan eksperimen untuk reaksi-reaksi fusi nuklir di atas.

\section{METODE}

Pada tahun 1973, Wong meninjau tanggul potensial untuk reaksi nuklir antara partikel bermuatan dengan pendekatan tanggul Coulomb melalui inversi potensial osilator harmonik berketinggian $V_{B}$ dan frekuensi $\omega_{l}$. Untuk energi $E$, probabilitas $P(l, E)$ untuk absorpsi dari gelombang parsial ke- $l$ diberikan oleh persamaan Hill-Wheeler ${ }^{[15]}$ :

$$
P(l, E)=\frac{1}{1+\exp \left[V_{B}-E\right] / \hbar \omega_{l}}
$$

dengan, $P(l, E)=$ probabilitas, $V_{B}=$ tanggul potensial atau biasa disebut sebagai tanggul Colomb $(\mathrm{MeV}), E_{0}=$ energi $(\mathrm{MeV}), \hbar \omega_{i}=$ kelengkungan $(\mathrm{MeV})$.

Dengan berpijak pada Persamaan 1, maka Wong dapat merumuskan secara analitik formula untuk menghitung tampang lintang reaksi fusi sebagai ${ }^{[3,7,16,17,18]}$.

$$
\sigma_{f}(E)=\frac{R_{B}^{2} \hbar \omega_{B}}{2 E} \ln \left\{1+\exp \left[\frac{2 \pi}{\hbar \omega_{B}}\left(E-V_{B}\right]\right\}\right.
$$

Dari Persamaan(4) tampak bahwa tampang lintang reaksi fusi bergantung pada tiga buah parameter terikat yaitu $V_{B}, R_{B}$, dan $\hbar \omega_{B}$ dengan $R_{B}$ merupakan posisi dimana tanggul Coulomb dan satu buah parameter bebas yaitu $E$. Nilai dari parameter-parameter terikat tersebut dapat diperoleh jika potensial total dari dua buah inti yang bereaksi diketahui. Potensial total ini merupakan gabungan dari potensial Coulomb yang sifatnya tolak menolak dan potensial inti yang sifatnya tarik menarik. Potensial total ini diberikan sebagai

$$
V_{(t o t)}(r)=V_{c}(r)+V_{N}(r)
$$

Suku pertama pada Persamaan 5 merupakan interaksi Coulomb dan diberikan sebagai

$$
V_{c}(r)=\frac{Z_{P} Z_{T} e^{2}}{r}
$$


dengan $Z_{P}$ dan $Z_{T}$ berturut-turut merupakan nomor atom inti proyektil dan nomor atom inti target. Sedangkan suku kedua merupakan potential inti yang dalam hal ini diasumsikan berbentuk potensial Akyuz-Winther ${ }^{[19]}$ yaitu

$$
V_{N}(r)=\frac{-V_{0}}{\left\{1+\exp \left[r-R_{0}\right] / a\right\}}
$$

Nilai parameter kedifusian pada Persamaan 7 diambil sebagai $a=0,63 \mathrm{fm}$ sedangkan parameter kedalaman, $V_{0}$, dan radius inti-inti yang bereaksi dihitung dengan menggunakan persaman-persamaan berikut.

$$
\begin{aligned}
& V_{0}=16 \pi \gamma \bar{R} a(\mathrm{MeV}) \\
& R_{0}=R_{P}+R_{T}+0,29(\mathrm{fm}) \\
& R_{T(P)}=1,233 A_{T(P)}^{1 / 3}-0,98 A_{T(P)}^{-1 / 3} \\
& \bar{R}=\frac{R_{T} R_{P}}{R_{T}+R_{P}}
\end{aligned}
$$

Pada Persamaan(8), nilai parameter tegangan permukaan, $\gamma$, dihitung menggunakan rumus

$$
\gamma=\gamma_{0}\left[1-k\left(\frac{\left(N_{T}-Z_{T}\right)\left(N_{P}-Z_{P}\right)}{A_{T} A_{P}}\right)\right]
$$

dengan $N_{T(P)}$ berturut-turut adalah jumlah netron inti target (proyektil), parameter $k=1,8$, dan parameter $\gamma_{0}=0,95 \mathrm{MeV} \mathrm{fm}^{2}$. Dengan demikian maka nilai potensial total pada Persamaan(5) dapat dihitung untuk setiap nilai $r$. Nilai $V_{B}$ diperoleh sebagai nilai tertinggi dari potensial totalnya sedangkan $R_{B}$ adalah posisi dimana nilai $V_{B}$ berada. Nilai parameter kelengkungan dihitung dengan menggunakan persamaan ${ }^{[3]}$.

$$
\hbar \omega_{B}=\hbar\left[\left(\left.\frac{d^{2} V(r)}{d r^{2}}\right|_{R_{B}}\right) / \mu\right]
$$

Dengan demikian maka tampang lintang reaksi fusi sebagai fungsi energy dapat dihitung dengan menggunakan Persamaan 4.

Untuk melihat keakuratan nilai tampang lintang yang diperoleh dengan formula Wong pada Persamaan 4 maka dilakukan perhitungan nilai chi-kuadrat menggunakan Persamaan 14.

$$
\chi^{2}=\frac{1}{N} \sum_{i=1}^{N} \frac{\left(\sigma_{\exp [i]}-\sigma_{\exp [i]}\right)^{2}}{\Delta \sigma_{\exp [i]}{ }^{2}}
$$

dengan $N$ adalah jumlah data dan $\Delta \sigma_{\text {exp }}$ adalah ralat dari data eksperimen. Jika nilai $\chi^{2}$ yang diperoleh semakin kecil maka kesesuaian antara nilai teori dan nilai semakin baik. Kesesuain sempurna anatar teori dan eksperimen terjadi jika diperoleh nilai $\chi^{2}=0$ [20].

\section{HASIL DAN PEMBAHASAN}

Pada bagian ini dilakukan perhitungan nilai tampang lintang reaksi fusi bagi reaksi nuklir ${ }^{12} \mathrm{C}+{ }^{12} \mathrm{C},{ }^{16} \mathrm{O}$, dan ${ }^{16} \mathrm{O}+,{ }^{16} \mathrm{O}$. Proses perhitungan dan simulasi numeriknya dilakukan dengan menggunakan Program Fusi16 [21] yang mengintegrasikan seluruh proses perhitungan menggunakan Persamaan 3-Persamaan 14. 


\section{Penentuan Nilai $V_{B}, R_{B}$, dan $\hbar \omega_{B}$}

Pertama-tama dilakukan perhitungan nilai-nilai $V_{B}, R_{B}$, dan $\hbar \omega_{B}$ untuk ketiga reaksi yang dikaji. Proses perhitungan nilai-nilai ini untuk reaksi inti ${ }^{12} \mathrm{C}+{ }^{12} \mathrm{C}$ serta potensial total yang dihasilkan ditunjukkan pada Gambar 1 . Hasil simulasi untuk reaksi ini memberikan $V_{B}=$ $6,180 \mathrm{MeV}, R_{B}=7,70 \mathrm{fm}$, dan $\hbar \omega_{B}=2,765 \mathrm{MeV}$. Dengan cara sama dilakukan untuk reaksi-reaksi ${ }^{12} \mathrm{C}+{ }^{16} \mathrm{O}$ dan ${ }^{16} \mathrm{O}+{ }^{16} \mathrm{O}$. Untuk reaksi ${ }^{12} \mathrm{C}+{ }^{16} \mathrm{O}$ diperoleh $V_{B}=8,04 \mathrm{MeV}, R_{B}=$ 7,90 fm, dan $\hbar \omega_{B}=2,931 \mathrm{MeV}$. Dan untuk reaksi ${ }^{16} \mathrm{O}+{ }^{16} \mathrm{O}$ memberikan hasil $V_{B}=$ $10,46 \mathrm{MeV}, R_{B}=8,10 \mathrm{fm}$, dan $\hbar \omega_{B}=3,08 \mathrm{MeV}$.

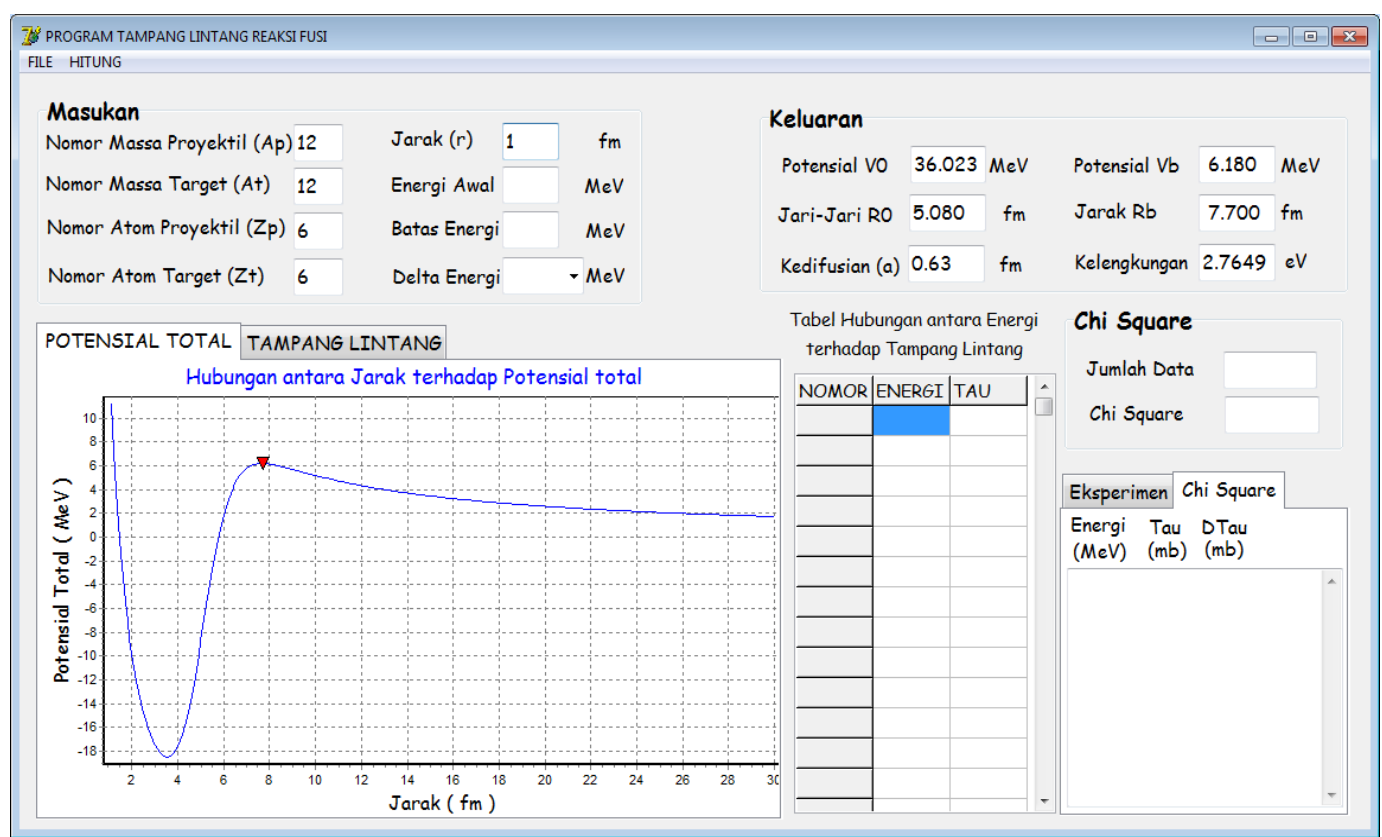

Gambar 1. (Colour online) Proses penentuan $V_{B}, R_{B}$, dan $\hbar \omega_{B}$ dan total potensial untuk sistem ${ }^{12} \mathrm{C}+{ }^{12} \mathrm{C}$

\section{Perhitungan Tampang Lintang Reaksi Fusi Nuklir}

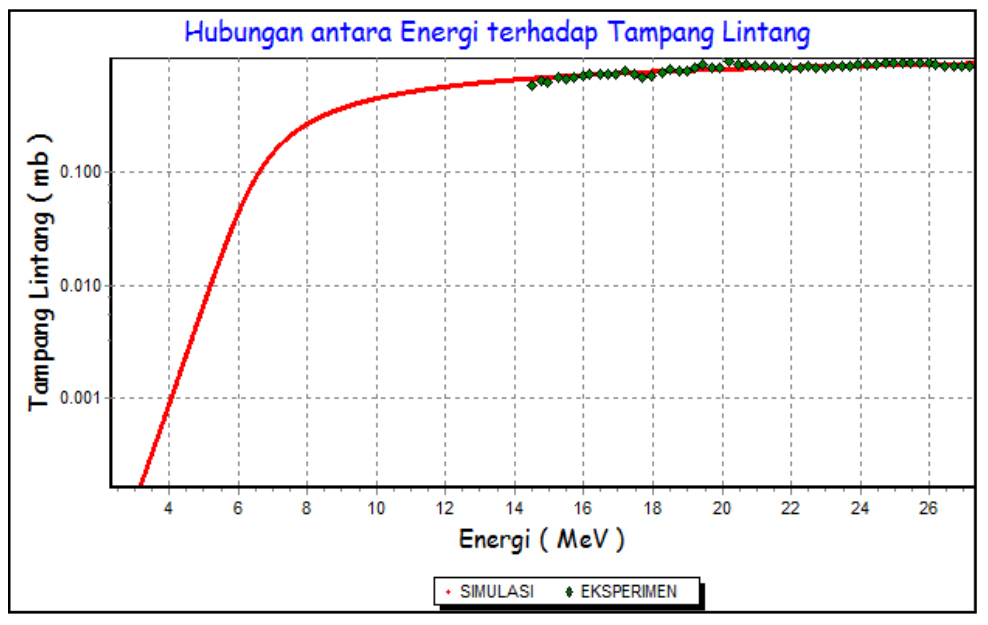

Gambar 2. (Colour online) Perbandingan tampang lintang reaksi fusi hasil simulasi dan hasil eksperimen untuk sistem ${ }^{12} C+{ }^{12} C$. Data Eksperimen diambil dari Ref. ${ }^{[10]}$.

Hasil perhitungan tampang lintang reaksi fusi untuk sistem ${ }^{12} \mathrm{C}+{ }^{12} \mathrm{C}$ ditunjukan pada Gambar 2. Hasil perhitungan ditunjukkan oleh garis merah sedangkan nilai eksperimen ditunjukkan oleh titik-titik hitam. Tampak bahwa hasil perhitungan sudah mengikuti kecenderungan data hasil ekperimen walaupun pada energi di atas $26 \mathrm{MeV}$ hasil 
perhitungan jauh melebihi nilai eksperimen. Hal ini sudah dapat dijelaskan oleh Rowley dan Hagino ${ }^{[5]}$ dengan menggunakan formula Wong umum. Namun ini diluar dari pembahasan yang dilakukan dalam makalah. Hasil perhitungan nilai chi-kuadrat memberikan hasil $\chi^{2}=11,07$. Hasil ini menunjukkan bahwa nilai teori sudah mendekati nilai eksperimen.

Gambar 3 menunjukkan perbandingan grafik antara nilai tampang lintang hasil simulasi dan nilai tampang lintang hasil eskperimen untuk sistem ${ }^{16} \mathrm{O}+{ }^{12} \mathrm{C}$. Hal ini dapat dilihat dengan kasat mata dari grafik yang diperoleh menunjukkan bahwa kenaikan grafik dari perhitungan tampang lintang secara simulasi dapat mengukuti kontur grafik dari perhitungan tampang lintang hasil eksperimen. Nilai Chi-kquare untuk sistem ${ }^{16} \mathrm{O}+{ }^{12} \mathrm{C}$ adalah 1,79. Hasil ini menujukkan bahwa formula Wong dapat menjelaskan data eksperimen dengan sangat baik.

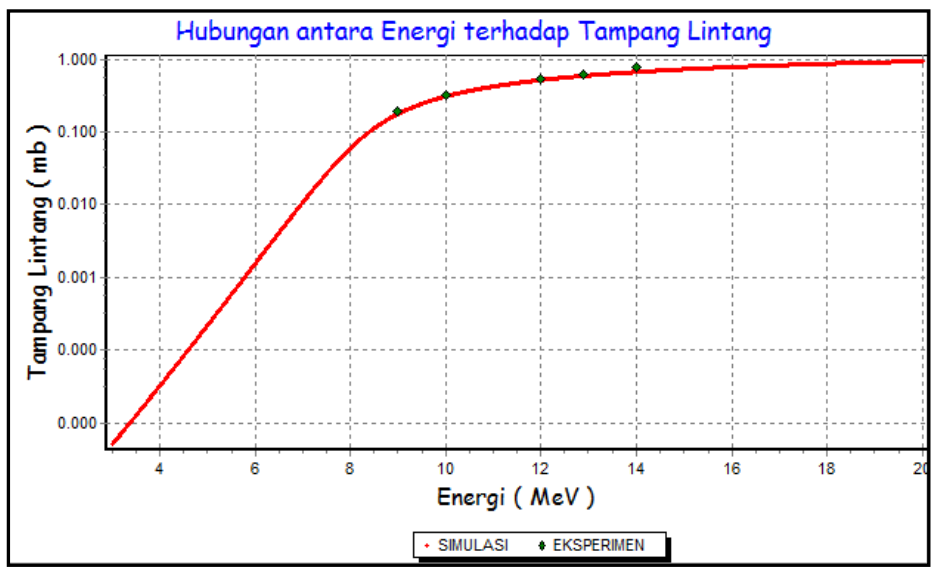

Gambar 3. (Colour online) Perbandingan tampang lintang reaksi fusi hasil simulasi dan hasil eksperimen untuk sistem ${ }^{16} \mathrm{O}+{ }^{12} \mathrm{C}$. Hasil perhitungan ditunjukkan oleh garis merah sedangkan nilai eksperimen ditunjukkan oleh titik-titik hitam Data Eksperimen diambil dari Ref. ${ }^{[11]}$.

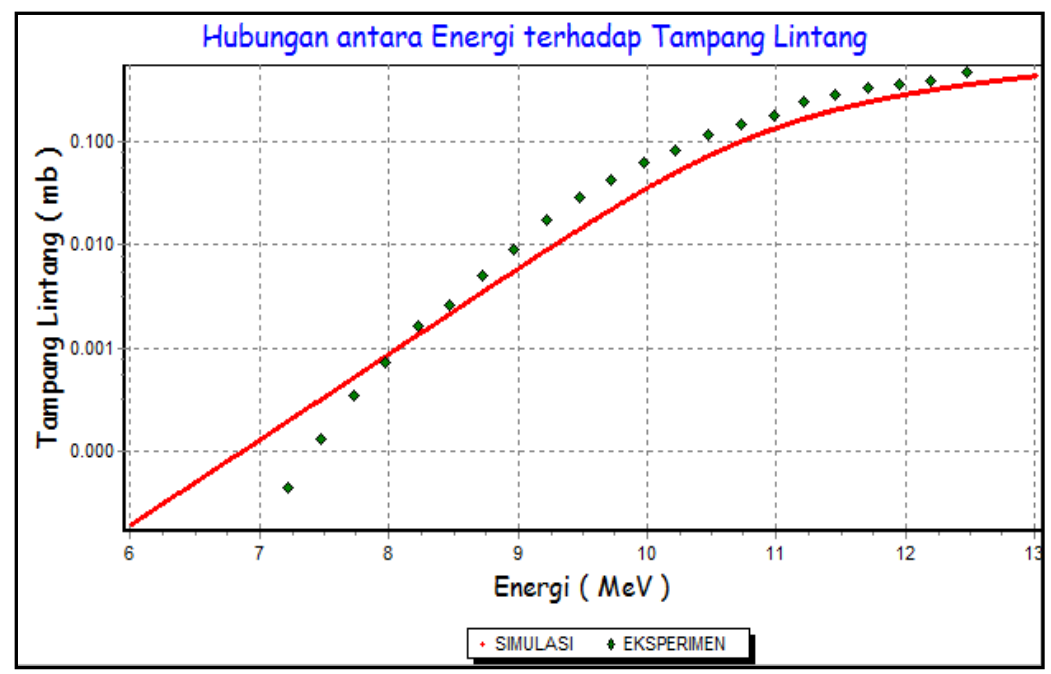

Gambar 4. (Colour online) Perbandingan tampang lintang reaksi fusi hasil simulasi dan hasil eksperimen untuk sistem ${ }^{16} \mathrm{O}+{ }^{16} \mathrm{O}$. Hasil perhitungan ditunjukkan oleh garis merah sedangkan nilai eksperimen ditunjukkan oleh titik-titik hitam Data Eksperimen diambil dari Ref. ${ }^{[11]}$.

Hasil simulasi tampang lintang sistem ${ }^{16} \mathrm{O}+{ }^{16} \mathrm{O}$ ditunjukkan pada Gambar 4. Hasil yang diperoleh kurang lebih sama dengan dengan hasil untuk sistem ${ }^{12} \mathrm{C}+{ }^{12} \mathrm{C}$ dan ${ }^{12} \mathrm{C}+{ }^{16} \mathrm{C}$ dimana hasil teroi sudah mengikuti kecendurngan hasil ekperimen. Namun dari Gambar 4 ini juga tampak bahwa hasil perhitungan untuk energy dibawah $8 \mathrm{MeV}$ melebihi nilai 
ekperimen sedangkan untuk energy di atas $9 \mathrm{MeV}$ nilai teori kurang dari nilai ekeprimen. Hal ini juga ditunjukkan dengan Chi-kuadrat yang cukup yaitu 73,44. Nilai ini jauh lebih besar dibandingkan dengan nilai Chi-kuadrat untuk sistem ${ }^{12} \mathrm{C}+{ }^{12} \mathrm{C}$ dan ${ }^{12} \mathrm{C}+{ }^{16} \mathrm{C}$. Jadi studi lebih lanjut perlu dilakukan untuk memperoleh hasil lebih baik.

\section{KESIMPULAN}

Telah dilakukan simulasi numerik perhitungan tampang lintang reaksi fusi untuk reaksireaksi nuklir ${ }^{12} \mathrm{C}+{ }^{12} \mathrm{C},{ }^{12} \mathrm{C}+{ }^{16} \mathrm{C},{ }^{16} \mathrm{O}+{ }^{16} \mathrm{O}$ dengan menggunakan formula Wong. Hasil simulasi menunjukkan bahwa hasil teori dapat menjelaskan hasil eksperimen dengan baik. Terutama untuk reaksi ${ }^{12} \mathrm{C}+{ }^{12} \mathrm{C}$ dan ${ }^{12} \mathrm{C}+{ }^{16} \mathrm{C}$ dimana nilai chi-kuadrat yang diperoleh juga cukup kecil. Untuk sistem ${ }^{16} \mathrm{O}+{ }^{16} \mathrm{O}$, walaupun secara umum hasil teori sudah mendekati hasil ekeprimen akan tetapi belum terlalu baik karena nilai chi-kuadrat yang diperoleh masih besar yaitu 73,44. Dengan demikian studi lebih lanjut perlu dilakukan dengan menggunakan Formula Wong Umum ${ }^{[5]}$ maupun dengan cara melakukan optimasi parameter-parameter dari potensial inti nuklir.

\section{DAFTAR PUSTAKA}

1. Wiyatmo, Y. 2006. Fisika Nuklir dalam Telaah Semi-Klasik dan Kuantum. Yogyakarta: Pustaka Belajar.

2. Darmadi, A. 2009. Fisika Inti dan Radioaktivitas. Universitas Negeri Yogyakarta, Yogyakarta.

3. Wong, C. Y. 1973. Interaction Barrier in Charged-Particle Nuclear Reactions. Phys. Rev., Vol. 31, No. 12.

4. Esbensen, H. 2012. Structures in High-Energy fusion data. Phys. Rev. C., Vol. 85, 064611.

5. Rowley, N., and Hagino, K. 2015. Examination of fusion cross sections and fusion oscillations with a generalized Wong formula. Phys. Rev. C. Vol. 91, 044617.

6. Wong, C. Y. 2012. Reaction Cross Section in Heavy-Ion Collisions. Phys. Rev. C., Vol. 86, 064603.

7. Balantekin, A. B. and Takigawa, N. 1998. Quantum tunneling in nuclear fusion. Rev. Mod. Phys., Vol. 70, No. 77.

8. Backerman, M. 1998. Sub-barrier fusion of two nuclei. Phys. Rep., Vol. 51, 1047.

9. Aziz, A. A., Yusof, N., Firihu, M. Z., and Kassim, H. A. 2015. Reliability of the double-folding potential for fusioncross sections of light systems. Phys. Rev. C, Vol. 91, 015811.

10. Kolata, J. J., Freeman, R. M., Haas, F., Heusch, B., and Gallmann, A. 1980. Reaction cross sections for ${ }^{12} \mathrm{C}+{ }^{12} \mathrm{C}$. Phys. Rev. C, Vol. 21, 579.

11. Eyal, Y., Beckerman, M., Chechik, R., Fraenkel, Z., and Stocker, H. 1976. Nuclear size and boundary effects on the fusion barrier of oxygen with carbon. Phys. Rev. C, Vol. $13,1527$.

12. Thomas, J., Chen, Y. T., Hinds, S., Meredith, D., and Olson, M. 1986. Sub-barrier fusion of the oxygen isotopes: A more complete picture. Phys. Rev. C, Vol. 33, 1679.

13. Barron-Palos, L., Aguilera, E. F., Aspiazu, J., Huerta, A., Martinez-Quiroz, E., Monroy, R., Mareno, E., Murillo, G., Ortiz, M. E., Policroniades, R., Verela, A., and Chavez, E. 2006. Absolute cross sections measurement for the ${ }^{12} \mathrm{C}+{ }^{12} \mathrm{C}$ system at astrophysically relevant energies. Nucl. Phys. A, Vol. 779, 318.

14. Spinka, H. and Winkler, H. 1974. Experimental determination of the total rection cross section of the stellar nuclear reaction ${ }^{16} \mathrm{O}+{ }^{16} \mathrm{O}$. Nucl. Phys. A, Vol. 233, 456.

15. Hill, D. L. and Wheeler, J. A. 1953. Nuclear Constitution and the Interpretation of fission Phenomena. Phys. Rev., Vol. 89, 1102. 
16. Santhosh, K. P. and Jose, V. B. 2014. Heavy-Ion Fusion Reactions of ${ }^{16} \mathrm{O}$ on Spherical/Deformed ${ }^{144-154}$ sm Targets Using Coulomb and Proximity Potentials. Nucl. Phys., Vol. 66, No. 4, pp. 939-951.

17. Godre, S. S. 2014. Classical simulations of heavy-ion fusion reactions and weaklybound projectile breakup reactions. Indian Academy of Sciences, Vol. 82, No. 5, pp. 879-891.

18. Frobrich, P. and Lipperheide, R. 1996. Theory of Nuclear Reactions. Hahn-Meitner Institude, Oxford Science Publications, Berlin.

19. Akyuz, R. O. and Winther, A. 1979. Parameterization Of The Nucleus-Nucleus Potential, edited by Broglia, R. A., Dasso, C. H., dan Ricci, R., North Holland, Amsterdam.

20. Wibirama, S. 2015. Distribusi Chi-Kuadrat (Chi-Square), Universitas Gajah Mada, Yogyakarta.

21. Justina. 2016. Simulasi Numerik Tampang Lintang Reaksi Fusi Nuklir yang Melibatkan Inti-Inti Ringan. Skripsi. Jurusan Fisika FMIPA, Universitas Halu Oleo.

22. Dasgupta, M., Hinde, D. J., Rowley, N., and Stefanini, A. M. 1948. Annu. Rev. Nucl. Part. Sci., Vol. 48, No. 401. 